\title{
Impact of PM2.5 concentration, weather and population on COVID-19 morbidity and mortality in Baghdad and Kuwait cities
}

\author{
Saadiyah H. Halos ${ }^{1}$ (1) - Ali Al-Dousari ${ }^{2} \cdot$ Ghofran R. Anwer $^{3} \cdot$ Amany R. Anwer $^{4}$
}

Received: 7 August 2021 / Accepted: 9 September 2021 / Published online: 28 October 2021

(c) The Author(s), under exclusive licence to Springer Nature Switzerland AG 2021

\begin{abstract}
The coronavirus (COVID-19) pandemic is a global health crisis and biggest challenge facing the world. Station measurements of fine particulate matter (PM2.5) concentration in Baghdad and Kuwait during the period January-July 2020 are analyzed as well as assessment of correlation between PM2.5, weather conditions (air temperature, relative humidity, wind speed), population density and COVID-19 morbidity and mortality. A significant improvement (decrease) has observed during total and partial curfew in PM2.5 at Baghdad by 35\%, 12.4\%, respectively, from PM2.5 mean during the study period that is less than the WHO recommended PM2.5 level especially in total curfew. This decrease in PM2.5 pollution and people's mobility in Baghdad at total and partial curfew contributed to decrease injuries and mortality. PM2.5 during total and partial curfew in Kuwait country witnessed increasing by $38.4 \%$ and decreasing by $22.3 \%$ from the PM2.5 mean, respectively, but still higher than WHO standard level. This increase in PM2.5 at total curfew was related to burning accidents in the oil wells which caused increasing in PM2.5 pollutant and then an increase in number of injuries and mortality during that time. In general during all study period our research found that PM2.5 and wind speed exhibit weak relation with COVID-19 morbidity and mortality but strong relation with increasing temperature and decreasing humidity. The high population density had a good association with increasing daily new cases, mortality due to COVID-19 pandemic. Thus, these factors may be taken into consideration in policy development for the control and prevention of new chains of the Coronavirus pandemic.
\end{abstract}

Keywords COVID-19 $\cdot$ PM2.5 $\cdot$ Weather $\cdot$ Population $\cdot$ Baghdad $\cdot$ Kuwait

\section{Introduction}

SARS-CoV-2 (Severe Acute Respiratory Syndrome-Coronavirus-2) is a new strain of coronavirus that was previously never identified in humans. The disease caused by this virus was referred to Corona virus disease-19 (COVID-19) (Crenn et al. 2020; WHO 2020a). The COVID-19 disease pandemic is causing significant social and economic affects

Saadiyah H. Halos

saadiyah.halos@gmail.com

1 Atmosphere and Space Science Center, Directorate of Space Technology and Communication, Ministry of Science and Technology, Baghdad, Iraq

2 Crisis Decision Support Program, Environment and Life Sciences Research Center, Kuwait Institute for Scientific Research, P.O. Box 24885, 13109 Safat, Kuwait

3 Iraqi Ministry of Health, Baghdad, Iraq

4 University of Baghdad / Al-Kindy College of Medicine, Baghdad, Iraq in large parts of the world and led to the worldwide application of unprecedented public protection measures (Crenn et al. 2020)., (Chafekar and Fielding 2018; WHO 2020a; Yao et al. 2020) showed that the highly contagious virus SARS-CoV-2 is a transform type of the previously existing coronaviruses Severe Acute Respiratory Syndrome-1 (SARS-CoV-1) and Middle East Respiratory Syndrome Corona Virus (MERS-CoV) where both caused an endemic epidemic in China in 2003 and in the Middle East especially in Saudi Arabia in 2012.

The spread of SARS-CoV-2 has already assumed epidemic proportions, affecting many countries within a short period, including Iraq and Kuwait. The Coronavirus pandemic spread in these two countries in late February 2020, and the results were positive for Corona virus infection associated with severe acute respiratory syndrome type 2 (SARS-CoV-2).

Particulate matter PM, as defined by the Environmental Protection Agency (EPA), is a term that denotes the collection of particles scattered in the air and be transported 
for enough time. These particles become from natural or artificial sources in several sizes (Xing et al. 2016; Mantecca et al. 2012). Ambient particulate matter with an aerodynamic diameter of $2.5 \mu \mathrm{m}$ (PM2.5) is an important component of the atmosphere and its sources can be natural or man-made. There are several of natural sources that pump millions of tons of particles into the atmosphere include wind, dust storms, forest fires, salt spraying, rock debris, and interactions between greenhouse gas emissions and soil erosion. Human activities such as fuel combustion, industrial processes, petroleum foundries, cement, fly ash emissions from power plants, coal burning, and agricultural waste also contribute to the fine particulate atmosphere (Yadav and Devi 2018). PM2.5 is present for a long time in the atmosphere and can penetrate deep into the lung. Long-term exposure to PM2.5 can cause health effects and premature death in humans (Pun et al. 2017) due to its insoluble pellets properties and theirs small size (Xing et al. 2016; Mantecca et al. 2012).

Iraq and Kuwait countries ranked as tenth and thirteen in world countries and second, fourth in western Asia region, respectively, in the most polluted countries by annual average PM2.5 concentration based on the data. Baghdad and Kuwait considered as the top most polluted capital cities of the world and listed as the eleventh, thirteen ranking, respectively, with an annual average of PM2.5 concentration. In the western Asia region, Baghdad and Kuwait cities considered as the top most polluted and heavily affected by dust/sandstorms in the summer months.

These months can experience nearly twice the PM2.5 levels as winter months. It arranged in 2019 as third and fifth ranks, respectively, with an annual mean of PM2.5 concentration that is over three times above the average annual WHO exposure recommendation (IQAir 2020). Sources of PM2.5 air pollution in the Middle East especially in Iraq and Kuwait include a mixture of natural sources, such as dust storms, and man-made sources, including energy production; transport and construction exhaust (UNEP 2016). Sandstorms contribute to high levels of PM2.5-year-round, their impact is noticeably seasonal and affecting air quality further in May through August. During these months, strong winds, thunderstorms, and low-pressure convective systems, because of intense heat, raise large amounts of dust. Dust particles have been found to comprise hydrocarbons, trace elements, heavy metals, sulfates, and nitrates (UNEP 2016).

Small particles can load the viruses, and they can live in them for several hours. SARS-CoV-2 is recognized to infect healthy people via aerosols (Van Doremalen et al. 2020; WHO 2020b) and so environmental factors may give partially explain the behavior and destiny of Corona Virus COVID-19 (Sharma et al. 2020; Sun and Han 2021). This shows that the virus can be transmitted and intensified by air pollution. In some areas, air quality is also up to the level required to breathe because they exceed the limit set by many international organizations, including the World Health Organization. Therefore, more care and precautions are proposed in such areas to prevent the severity of the disease (Wang et al. 2020).

A recent study estimated that the proportion of deaths because of COVID-19 worldwide that are attributable to exposure to fine particles is as high as $15 \%$. The basis for this estimate was the focus response function that developed by Pozzer et al. (2020) using data from two environmental studies. Air pollution acted as a causative factor for the diseases such as bronchitis, asthma, and many of the diseases of the respiratory system. Paital and Agrawal (2021) concluded that air pollution has positive effects on the rate of spread and intensity of COVID-19 cases, as the rate of infection and death was higher in the more polluted areas than other less polluted. PM2.5 has a great impact on human health and it can carry different toxic substances, passing through the filtrate nose hair, reaching the end of the respiratory system with airflow, and accumulate in the lungs causing damage in parts of the body (Xing et al. 2016). The levels of PM 2.5 among 21 cities around the world were lower at the lockdown phase than at any other time (Benchrif et al. 2021). In China PM2.5 levels decreasing by 31\%, 29\%, 24\% at southeast region, Northern Yangtze River Delta, Pearl River Delta, respectively, during COVID-19 outbreak (Li et al. 2021).

Karkour and Itsubo (2020) found that decreasing in human activities during the COVID-19 pandemic caused an important change in PM2.5 concentration and large reduction in mortality in the most polluted areas in the world: China, India and Nigeria. Brunekreef et al. (2021) showed that despite the available environmental studies on COVID-19 and air pollution, they do not allow an accurate estimate of the percentage of COVID-19 deaths worldwide because of PM2.5. Tan et al. (2005) indicated that the SARS outbreak was significantly related to changes in temperature in some China cities. Also, a positive relationship found by Ma et al. (2020); Xie and Zhu (2020) between COVID-19 deaths and meteorological parameters in Chinese cities. The results of Hamd et al. (2021) showed a relationship between meteorological parameters (temperature, humidity) with the spread of COVID-19 in Egypt.

The aim of this study is to explore of association between environment conditions including ambient pollutants PM2.5 and weather variables, population, and COVID-19 incidence/mortality in some regions in the Middle East like Iraq (Baghdad) and Kuwait country and made a comparison for the level of PM2.5 and COVID-19 cases during the total and partial curfew. 


\section{Methods and modeling}

\section{Data collection}

Because PM2.5 concentrations data for stations across Iraq were not available during the Corona pandemic, hourly PM2.5 concentration data from US Embassy air quality station in Baghdad city is adopted in this study. This data was measured by GAIA air quality monitoring station that using high-tech laser particle sensors to measure in realtime PM2.5 pollution, which is one of the most harmful air pollutants. Hourly weather variables (temperature (T), relative humidity (RH) and wind speed (WS)) for Baghdad city is taken from air quality open data platform worldwide COVID-19 dataset (https://aqicn.org/data-platform/covid19/ verify/c0575f89-134b-4014-831c-298768a7411c).

Hourly PM2.5 and weather variables are provided from Kuwait stations (Ahmadi, Manorial, Saad Al-abdulla in addition to US Embassy station located in Kuwait city for the period from 1 Jan to 31 July 2020.

The counts of COVID-19 cases in Baghdad city were taken from official reports of the Iraqi Ministry of Health in web site (https://www.facebook.com/MOH.GOV.IQ/), which included daily positive diagnoses, recovered and deceased of COVID-19 cases. COVID-19 incidence counts in Kuwait country were provided by Kuwait's Ministry of Health.

The Kuwait daily case counts of positive diagnoses, recovered and deceased of COVID-19 are taken from web site (https://corona.e.gov.kw/Ar/Home/CasesByDate). All these data were collected during the period from late February to December 31,2020 to describe the evolution of COVID-19 in Baghdad city and Kuwait country.

\section{Statistical analysis methods}

Descriptive analyses were performed for PM2.5 and all COVID-19 cases observations for Baghdad city and Kuwait country. For almost all statistical computations, the mean and standard deviation are used to describe the data in this study. The mean $(\bar{x})$ and standard deviations (STD) are applied on hourly PM2.5 concentration measurements over Baghdad and Kuwait stations during study period. These also applied on the hourly meteorological elements values such as air temperature, relative humidity and wind speed:

$\bar{x}=\frac{1}{n} \sum_{i=1}^{N} x_{i}$,

$\operatorname{STD}=\sqrt{\frac{\sum(x-\bar{x})^{2}}{n-1}}$, where $n=$ sample size, $\bar{x}=$ samples mean, $S T D=$ sample standard deviation (Weiss 2015).

Percentage frequency is used to find the amount of a variable in terms of 100 , and it is mainly used to compare and find out ratios. The percentage formula used for PM2.5 is,

Percentage of days with PM2.5 $>$ WHO recommended PM 2.5 level $\left(25 \mu \mathrm{g} / \mathrm{m}^{3}\right)=$ (no. of days where concentration exceed the WHO standard/Total account $) \times 100$.

To summarize the shape of distribution and variability of daily PM2.5 concentrations during total and partial curfew for Baghdad and Kuwait country, Box and whisker plots by using Origin 2019b software. This type of graph shows the minimum, first quartile, median, third quartile and maximum of daily PM2.5 concentrations.

The correlation coefficient $(r)$ is an important tool to measure the strength of the linear relationship between two variables and their association with each other. To assess the correlation between PM2.5 and Corona cases and some metrological variables, Person correlation coefficients is used as follow in equation:

$$
r=\frac{n\left(\sum x y\right)-\left(\sum x\right)\left(\sum y\right)}{\sqrt{\left[n \sum x^{2}-\left(\sum x\right)^{2}\right]\left[n \sum y^{2}-\left(\sum y\right)^{2}\right]}}
$$

where, $n=$ the number of sample observed variable, $\Sigma x y=$ sum of the products of paired variables, $\Sigma x=$ sum of $x$ variable, $\Sigma y=$ sum of $y$ variable, $\Sigma x^{2}=$ sum of squared $x$ variable, $\Sigma y^{2}=$ sum of squared $y$ variable.

This study includes three stages of analysis: first; descriptive analyses were performed for all the COVID-19 cases and PM2.5 data for Baghdad and Kuwait country, Second; to assess the effect of total and partial curfew on air quality indicator (PM2.5) and COVID-19 cases and third; to analyze the associations of PM2.5, population and metrological factors with COVID-19 morbidity and mortality during the study period from late February to 31 July 2020.

\section{Results and discussions}

\section{Temporal evolution of the COVID-19 cases}

The Coronavirus pandemic spread in Iraq, starting from February 24, 2020 in the city of Najaf, when a sample of an Iranian religious student was examined and the result was positive for his infection with Corona virus disease associated with SARS-CoV-2.

Iraqi Ministry of Health registered the first case on February 272020 and designated it as "Day-zero" in the capital, Baghdad, of a 42-year-old man who was returning from Iran and was placed in health custody at the Euphrates general hospital. Figure 1 presents the temporal pattern of the daily 
Fig. 1 Daily COVID-19

incidence count of confirmed injury, recovered, deceased and there cumulated numbers during year 2020 for a Baghdad, b Kuwait
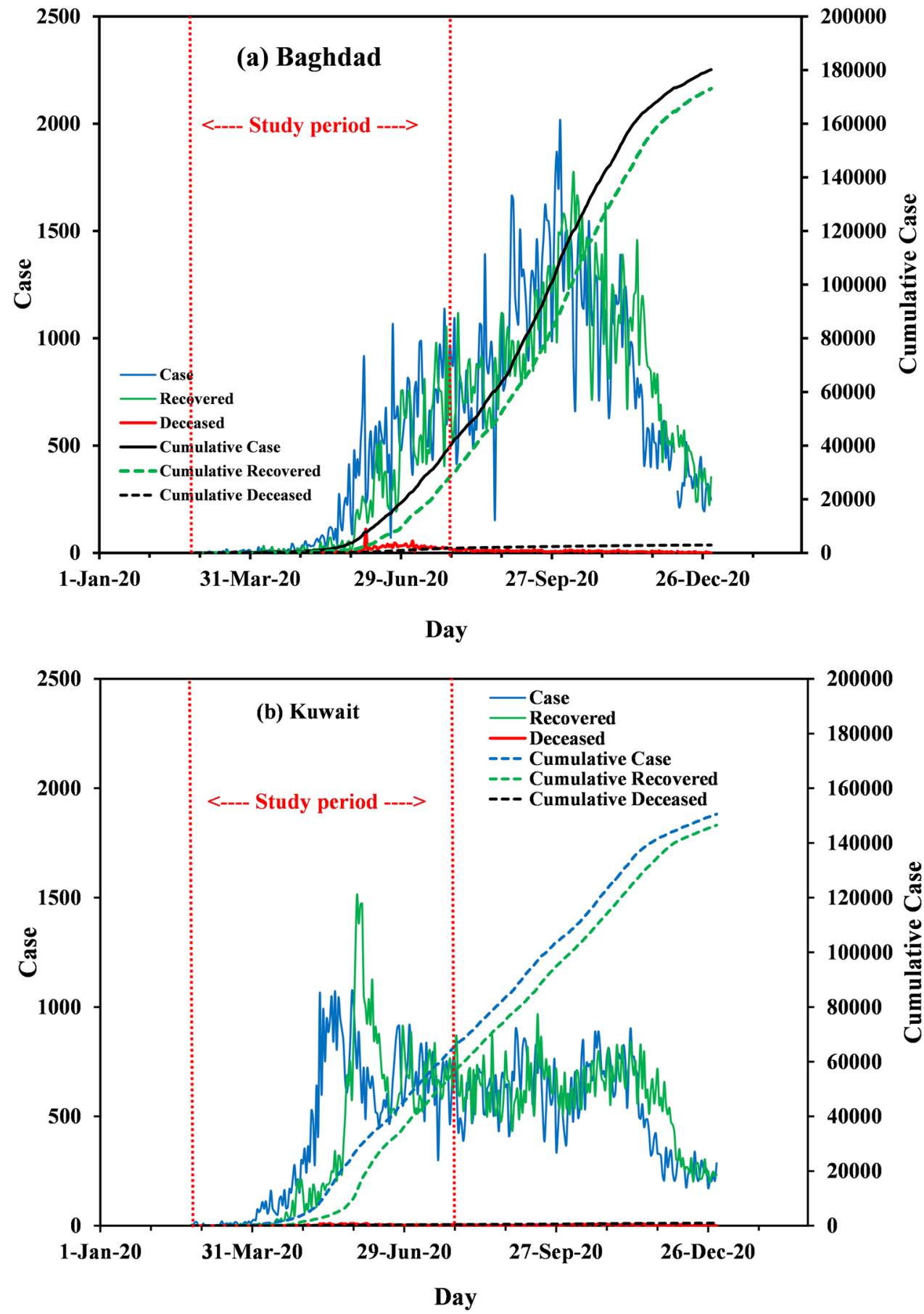

confirmed COVID-19 cases, recovered, deceased and cumulated (cases, recovered, deceased) over Baghdad and Kuwait during year 2020.

The cases began to increase and the first two deaths due to the COVID-19 virus were reported on 4 March, 2020. From official reports of Iraqi Ministry of Health for cumulative cases in Baghdad at 2020-12-31 were 180,196, of these
$96 \%(173,101)$ have recovered and about 2\% (2923) were died. Peaks in daily cases (date), recovered (date) and deaths (date) in Baghdad were 2016 (2-Oct-2020), 1773 (10-Oct2020), and 111 (8-Jun-2020), respectively.

The first injury recorded by the Kuwait's Ministry of Health was in 24 February 2020 and then the cases began to increase. The first death due to the COVID-19 virus was 
Fig. 2 Temporal variations in 24-h average concentrations of air pollutant PM2.5 (line) over a Baghdad b four Kuwait cities (Ahmadi, Manorial, Sad-Al Abdulla and Kuwait) for the period (1 January-31 July 2020). The $24 \mathrm{~h}$ average of WHO PM2.5 guideline (red dashed lines)
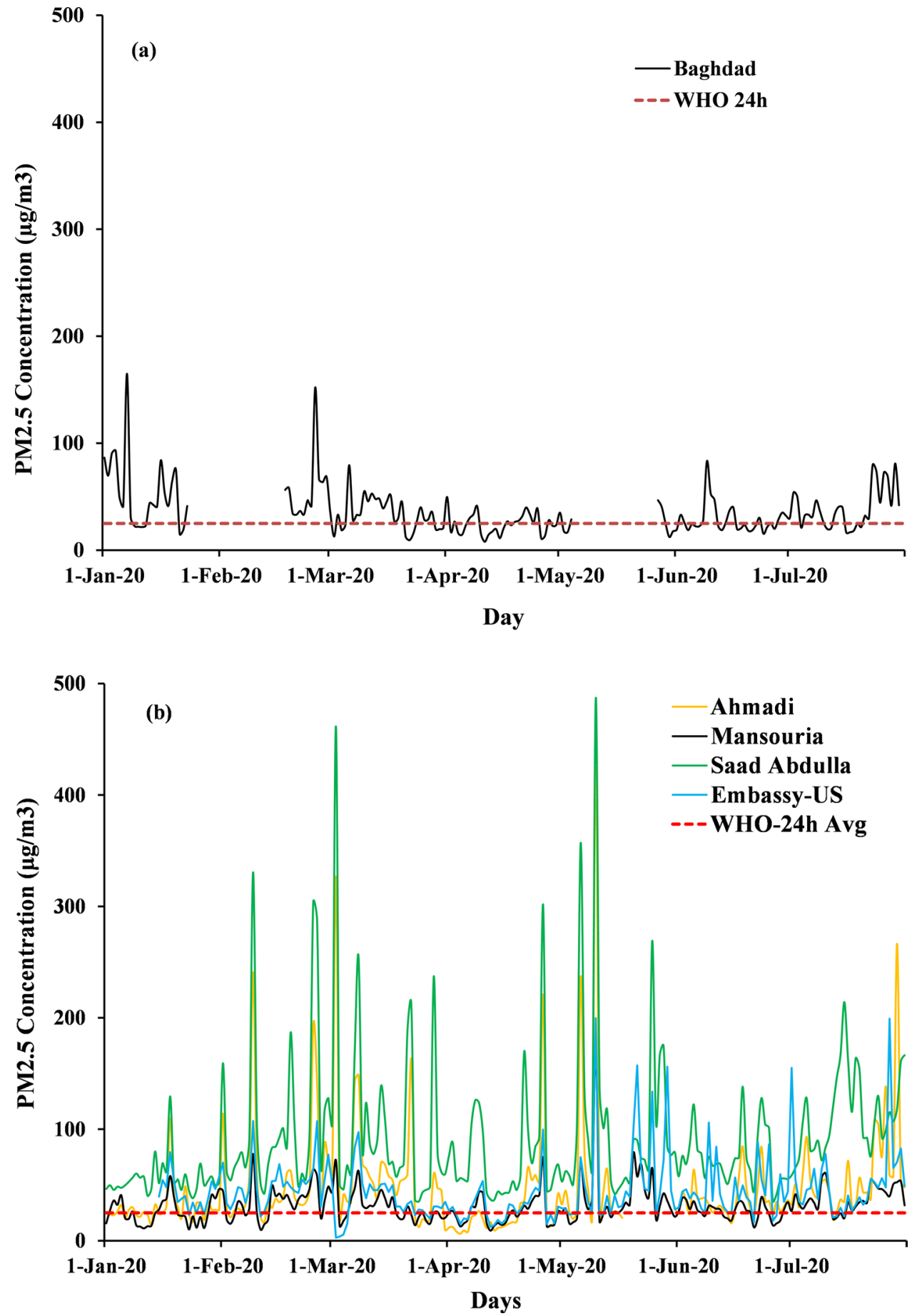

reported on 4 April 2020. As of 31 December, 2020, the reported total confirmed COVID-19 cases to 150,585 , of these $97 \%(146,518)$ have recovered and about 1\% (934) was died. The month of May witnessed the highest number of injuries and deaths in Kuwait country where the official reports recorded the highest peak of daily cases reached to 1073 on 19-May-2020 and 11 deaths, on 16-May-2020. In year 2020 Baghdad was the city with highest cases and deaths of COVID-19 outside of Kuwait country.

\section{Variations in PM2.5 concentration in Baghdad city and Kuwait country}

Figure 2a, b illustrate $24 \mathrm{~h}$ mean of ambient air pollutant PM2.5 in Baghdad and four Kuwait cities (Ahmadi, Mansouria, Sad-Al Abdulla and Kuwait) during COVID-19 pandemic period from 1 January to 31 July 2020 with WHO $24 \mathrm{~h}$ average standard $\left(25 \mu \mathrm{g} / \mathrm{m}^{3}\right)$. It is found that most days 
Table 1 Statistical analysis of daily PM2.5 concentration during the period from 1 January to 31 July 2020

\begin{tabular}{|c|c|c|c|c|c|c|}
\hline \multirow[t]{2}{*}{ Statistic parameters } & \multirow{2}{*}{$\begin{array}{l}\text { Iraq } \\
\text { Baghdad }\end{array}$} & \multicolumn{4}{|l|}{ Kuwait } & \multirow{2}{*}{$\begin{array}{l}\text { Percentage } \\
\text { Mean Kuwait } \\
\text { country }\end{array}$} \\
\hline & & Ahmadi & Mansouria & Saad-Abdulla & Kuwait-city & \\
\hline Mean & 36.2 & 48.4 & 31.6 & 92.6 & 45.2 & 54.7 \\
\hline Standard deviation & 22.7 & 52.6 & 16.8 & 66.1 & 29.3 & 36 \\
\hline Minimum & 7.9 & 6.2 & 9.0 & 35.0 & 2.7 & 18.2 \\
\hline Maximum & 164.9 & 437.3 & 170.2 & 487.0 & 199.8 & 323.6 \\
\hline Count & 165 & 200 & 213 & 213 & 199 & 213 \\
\hline Days of PM2.5 > WHO & $77 \%$ & $72 \%$ & $63.4 \%$ & $99.5 \%$ & $80 \%$ & $79 \%$ \\
\hline
\end{tabular}

in all cities are exceeding standard WHO $24 \mathrm{~h}$ average exposure recommended.

A statistical summary of the PM2.5 data is shown in Table 1 for the study period. This table includes daily measures of mean, standard deviation, minimum, maximum, count and percentage of days with PM2.5 concentration exceed the $24 \mathrm{~h}$ average WHO standard $\left(25 \mu \mathrm{g} / \mathrm{m}^{3}\right)$ as well as the statistical summary for Kuwait country which obtained for four stations.

In general, when comparing the cities presented in Table 1, it's found that the daily mean of ambient PM2.5 with standard deviations for Baghdad and Mansouria have the lower values than for other study cities. In term of days percentage of PM2.5 concentration exceed WHO standard, all study cities exceed the WHO standard $\left(25 \mu \mathrm{g} / \mathrm{m}^{3}\right)$. SaadAl Abdulla, Kuwait city are considered as the most polluted in terms PM2.5 concentration flowed by Baghdad, Ahmadi, Mansouria cities due to many reasons such as traffic volume, industrial emissions, oil refinery, power plants, land use and population size can alter the concentration of PM2.5.

\section{Variations in PM2.5 concentration during total and partial curfew}

In Baghdad the total curfew applied on days (Thursday, Friday and Saturday) in Jun month 2020 and partial curfew in hours (7 PM-5 AM) of days (Sunday to Wednesday) in Jun month. In Kuwait the curfew applied as total curfew on days

Table 2 Population density, area and COVID-19 cases in Baghdad and Kuwait country in 2020

\begin{tabular}{|c|c|c|}
\hline & Baghdad & Kuwait Country \\
\hline Population size & $(7,144,000)^{*}$ & $(4,270,571)^{*}$ \\
\hline Area $\left(\mathrm{Km}^{2}\right)$ & $(4555)^{*}$ & $(17,818)^{*}$ \\
\hline People per $\mathrm{Km}^{2}$ & 1568 & 240 \\
\hline Total Infection & 180,196 & 150,585 \\
\hline Mortality pers (number) & $2 \%(2923)$ & $1 \%(934)$ \\
\hline
\end{tabular}

*Data source United Nations-World Population Prospects (https:// population.un.org/wpp/)
10-30 May 2020 and partial curfew hours start from 7 PM until 5 AM of days in Jun month 2020.

The socio-economic lockdown include schools, universities, shopping centers and other large gathering places will remain closed, as will the country's international airports. The curfew excludes employees of the Ministry of Health, the security forces and government departments providing essential services. It also excludes grocery, fruit and vegetable stores, bakeries and pharmacies which will be allowed to open from 5 AM to 7 PM when the total curfew is in force. This lockdown resulted in a major social and economic relapse, but on the other hand, it had a significant positive impact on air quality and a relatively lower prevalence of COVID-19 virus.

Substantial reduction in ground concentrations of PM2.5 was observed during total curfew period at Baghdad is clearly reflected in Fig. 3a. Significant decrease in total curfew days of about 35\% from PM2.5 mean during the study period can be seen in Baghdad city and was less than WHO standard by $\left(1.5 \mu \mathrm{g} / \mathrm{m}^{3}\right)$.

In partial curfew period in Jun month, the daily PM2.5 was decrease of about $12.4 \%$ from study period PM2.5 mean. These observed changes in PM2.5 concentrations improved air quality of Baghdad city during total and partial curfew period. This decrease of ambient air pollution can be related to socio-economic lockdown and decreasing of vehicle traffic. The decrease of ambient air pollution in Baghdad in total and partial curfew contributed to a decrease in injuries and deaths to be 551, 26 and, respectively.

Table 3 Minimum and maximum of PM2.5 and weather parameters

\begin{tabular}{llllll}
\hline Variables & \multicolumn{2}{l}{ Baghdad } & & \multicolumn{2}{l}{ Kuwait country } \\
\cline { 2 - 3 } & Min. & Max. & & Min. & Max. \\
\hline PM2.5 $\left(\mu \mathrm{g} / \mathrm{m}^{3}\right)$ & 7.9 & 164.9 & & 10 & 323.6 \\
$\mathrm{~T}\left({ }^{\circ} \mathrm{C}\right)$ & 6 & 41 & & 7.9 & 44.7 \\
RH $(\%)$ & 15 & 93 & & 8.2 & 80.7 \\
WS $(\mathrm{m} / \mathrm{s})$ & 1 & 8.2 & & 0.9 & 4.6 \\
\hline
\end{tabular}


Fig. 3 Boxplot of daily PM2.5 concentrations $(\mu \mathrm{g} / \mathrm{m} 3)$ during total and partial curfew for a Baghdad and b Kuwait country. WHO $24 \mathrm{~h}$ average standard (red line) and PM2.5 mean for study period (blue line)
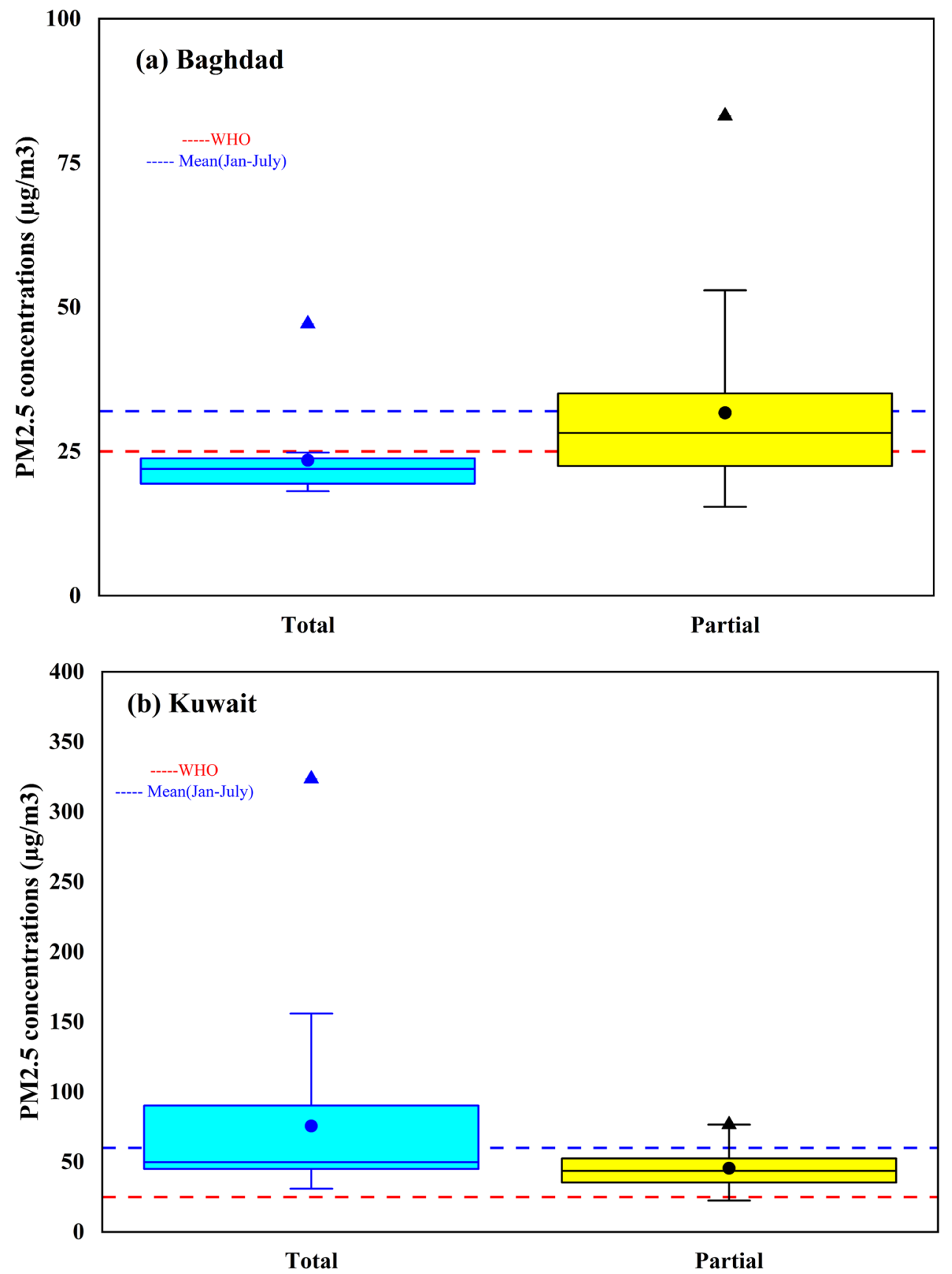

The daily mean of PM2.5 concentration was calculated for Kuwait country stations in four cities (Ahmadi, Manorial, Saad-Al Abdulla and Kuwait). Figure 3b illustrated PM2.5 concentrations during total and partial curfew in Kuwait country.

It is found that PM2.5 concentration in partial curfew was less than the mean during the study period by (22.3\%) but still higher than WHO $24 \mathrm{~h}$ average standard.

During the total curfew, the PM2.5 concentration mean was higher than the PM2.5 mean for study period by $38.4 \%$ and higher than WHO $24 \mathrm{~h}$ average standard. However, air quality was not improved significantly in Kuwait country. It has improved a lot in Baghdad city but in Kuwait it did not change at all, although absence of traffic vehicles and control industrial activities. This strange increase in PM2.5 related to the occurrence of burning accidents in the oil wells which caused increase in the number of injuries and deaths during that period.

\section{Impact of PM2.5 concentration on infections and mortality during COVID-19 pandemic}

During the period (1 January-31 July 2020), Baghdad and Kuwait country have high levels of PM2.5 and poor air 
Table 4 Pearson correlation coefficients between COVID-19 cases and PM2.5 concentration and weather parameters during the period (27 Feb-31 Jul 2020)

\begin{tabular}{|c|c|c|c|c|c|c|c|c|}
\hline \multirow[t]{2}{*}{ COVID-19 } & \multicolumn{4}{|c|}{ Baghdad } & \multicolumn{4}{|l|}{ Kuwait } \\
\hline & PM2.5 & WS & RH & Temp. & PM2.5 & WS & $\mathrm{RH}$ & Temp. \\
\hline Cases & 0.15 & 0.06 & -0.66 & 0.84 & 0.12 & 0.08 & -0.67 & 0.83 \\
\hline Deaths & 0.16 & 0.09 & -0.53 & 0.66 & 0.09 & 0.16 & -0.55 & 0.59 \\
\hline Cum. Cases & 0.25 & -0.01 & -0.58 & 0.80 & 0.06 & 0.11 & -0.50 & 0.89 \\
\hline Cum. Deaths & 0.23 & 0.00 & -0.57 & 0.80 & 0.05 & 0.14 & -0.54 & 0.90 \\
\hline
\end{tabular}

quality as shown in Table 1 which are higher than WHO $24 \mathrm{~h}$ average standard. Our findings associations of total infections as 31 July 2020 for Baghdad and Kuwait $(42,425$, $66,957)$, respectively, were positively related to percentage of days with PM2.5 exceed WHO standard (77\% and 79\%) during COVID-19 pandemic. The findings of most studies demonstrate that both short term and long-term exposure to air pollution especially PM2.5 may contribute significantly to higher rates of COVID-19 infections and mortalities (Ali and Islam 2020).

\section{Correlation population density on COVID-19 cases}

In this study, properties of the COVID-19 infection associated with various two population densities have examined in two regions; Baghdad city and Kuwait country. It's noted that population density has a strong association with total infection cases and mortality from the beginning of the Corona pandemic until the end of a year 2020 which illustrated in Table 2. The total infection, percentage (number) of mortality of COVID-19 in Baghdad 180,196, 2\% (2923) was higher than that recorded in Kuwait 150,585, $1 \%$ (934). This is attributed to social affinity where the population density in Baghdad was (1568 people per $\mathrm{Km}^{2}$ ) while in Kuwait was (240 people per $\mathrm{Km}^{2}$ ).

There are studies in the world considered the population size an effective parameter for evaluation and has highest correlations were observed for COVID-19 cases (Şahin 2020). Moderate association between COVID-19 virus spread and population density in the context of India was found by (Bhadra et al. 2021).

\section{Correlation of COVID-19 morbidity and mortality with PM2.5 and metrological parameters}

PM2.5 and three weather factors T, RH, WS are considered in the study and evaluated for Baghdad and Kuwait country during COVID-19 pandemic as for July 31, 2020. Table 3 shows the minimum and maximum of daily mean of PM2.5, T, RH and WS during COVID-19 pandemic in 2020. It's noticed that each of PM2.5 and T are higher in Kuwait country than that for Baghdad city during the study period) are higher than that for Baghdad, but the opposite was with the RH and WS.
Table 4 presents the result of Pearson correlation analysis for daily mean of our variables of interest (PM2.5, T, RH and WS) with COVID-19 (daily new cases, daily new deaths, cumulative cases and cumulative deaths) during Corona pandemic. Correlation results between pairs of variables are almost the same for Baghdad and Kuwait country implying that all variables tend to vary in the same direction together. Values of coefficients for COVID-19 daily new cases and deaths, cumulative cases and deaths with PM2.5 are positive, but weak. The relationship may be complex and not linear and depends on the history period of exposure to polluted air with the fine particulate matter that can penetrate the lungs. It was found through clinical examination in isolation hospitals for Corona patients that severe cases and deaths are those who have a bad history of respiratory diseases such as asthma. Another reason may be the PM2.5 particles sizes $(2.5 \mu \mathrm{m})$ were significantly larger compared to the size of the SARS-CoV-2 virus of range (60-140 nm) which determined under Transmission Electron Microscope (Zoran et al. 2020). In another recent study, six virus-like particles in patients with confirmed SARS-CoV-2 infection were $70-110 \mathrm{~nm}$ in diameter (Zhu et al. 2020b; Menter et al. 2020).

Table 4 illustrated that temperature was strongest positively correlated with daily new cases, daily new deaths, cumulative cases and cumulative deaths. Relative humidity was strong negatively correlated with daily new cases and daily new deaths, cumulative cases and cumulative deaths. Effects of daily mean temperature was positively related to the daily new cases and daily new deaths. A $1{ }^{\circ} \mathrm{C}$ increase in temperature was associated with a $0.6 \%, 0.3 \%$ increase in daily new cases and a $0.03 \%, 0.003 \%$ increases in daily new deaths. A $1 \%$ reduction in relative humidity was associated with a $0.26 \%, 0.15 \%$ increase in daily new cases and a $0.01 \%, 0.002 \%$ increases in daily new deaths. The cases of infection increased in Baghdad and Kuwait despite the imposition of the curfew in summer and the number of injuries increased with increasing temperatures in spring and summer months as shown in Fig. 1. But this study consistent with the results conducted by Şahin 2020; Chan et al. 2011, which shows the inverse correlation of relative humidity with virus infections and may be eliminating the virus viability. 
Wind speed has positive but weak correlation with daily new cases, daily new deaths, cumulative cases and cumulative deaths. Adekunle et al. 2020 reported a significant positive association with wind speed, where a $1 \%$ increase in average wind speed was associated with $11.21 \%$ increase in COVID-19 cases in countries in Africa. Bashir et al. 2020: Bukhari et al. 2020; Menebo 2020 and Zhu et al. 2020a did not report a significant association between wind speed and daily cases of COVID-19.

\section{Conclusions}

The present study investigated the effects of environment pollutant PM2.5, metrological factors, population and the decisions of the government policy to impose a curfew on COVID-19 in Baghdad city and Kuwait country.

Ground-based observations indicated that air quality by PM2.5 levels in Baghdad city and Kuwait cities have high concentration exceed the WHO standard. Significant improvement has been observed during total and partial curfew in the measured concentration of PM2.5 levels contributed to a decrease in injuries and deaths in Baghdad. PM2.5 concentrations during partial curfew in Kuwait witnessed decreasing by $(22.3 \%)$ but still higher than WHO $24 \mathrm{~h}$ average standard but witnessed increased in total curfew by (38.4\%) from PM2.5 mean of study period related to occurrence of burning in accidents in the oil wells which caused to increase in the number of injuries and deaths during that period.

The results indicated that daily confirmed cases of COVID-19 were significant correlated positively with daily mean temperature and negatively with daily mean relative humidity. It noted that weather is a significant contributing factor to COVID-19 transmission, particularly temperature and humidity while other weather and air pollutants exhibit no significant relation with COVID-19 pandemic.

In addition to above, the correlation between the population density and the COVID-19 total infections, mortality in year 2020 indicate that the region with high population is closely related to the higher number of COVID-19 infections and percentage of mortality.

The possibility of a second or third wave of the COVID virus may continue to arise. So there necessary to be a further analysis of the COVID-19 pandemic to understand the impact of weather on future outbreaks, and how helps to take healthy prevention measures. Also it may be need a long-term study of the extent of exposure to high levels of pollution and to patients who have a history of asthma and respiratory diseases.
Author contributions SHH analyzed the data and wrote the manuscript. AA supplied the Kuwait stations data and Corona injuries data. GRA revised the manuscript. ARA collected Baghdad Corona data.

Funding This study was not funded.

Availability of data and materials All datasets used in the current study are available from the corresponding author upon request.

\section{Declarations}

Conflict of interest The authors declare that they have no competing interests.

Ethical approval and consent to participate Not applicable.

Consent for publication All authors agreed to publish the manuscript.

\section{References}

Adekunle I, Tella S, Oyesiku K, Oseni I (2020) Spatio-temporal analysis of meteorological factors in abating the spread of COVID-19 in Africa. Heliyon 6(8):e04749. https://doi.org/10.1016/j.heliyon. 2020.e04749

Ali N, Islam F (2020) The effects of air pollution on COVID-19 infection and mortality - a review on recent evidence. Public Health Front. https://doi.org/10.3389/fpubh.2020.580057

Bashir M, Ma B, Komal B, Bashir M, Tan D, Bashir M (2020) Correlation between climate indicators and COVID-19 pandemic in New York, USA. Sci Total Environ 728:138835

Benchrif A, Wheida A, Tahri M, Shubbar R, Biswas B (2021) Air quality during three covid-19 lockdown phases: AQI, PM2. 5 and $\mathrm{NO} 2$ assessment in cities with more than 1 million inhabitants. Sustain Cities Soc 74:103170

Bhadra A, Mukherjee A, Sarkar K (2021) Impact of population density on Covid-19 infected and mortality rate in India. Model Earth Syst Environ 7(1):623-629

Brunekreef B, Downward G, Forastiere F, Gehring, U, Heederik D, Hoek G, Koopmans M, Smit L, Vermeulen R (2021) Air pollution and COVID-19. Policy Department for Economic, Scientific and Quality of Life Policies Directorate-General for Internal Policies, European Parliament, Luxembourg. http://www.europarl.europa. eu/supporting-analyses

Bukhari Q, Massaro J, D'Agostino RB, S, Khan S, (2020) Effects of weather on coronavirus pandemic. Int J Environ Res Public Health 17(15):5399

Chafekar A, Fielding B (2018) MERS-CoV: understanding the latest human coronavirus threat. Viruses 10(2):93

Chan KH, Peiris JSM, Lam SY, Poon LLM, Yuen KY, Seto WH (2011) The effects of temperature and relative humidity on the viability of the SARS coronavirus. Adv Virol. https://doi.org/10.1155/2011/ 734690

Crenn V, El Kinani M, Pietu G, Leteve M, Persigant M, Toanen C, Varenne Y, Goffinet N, Buffenoir K, Montassier JF, E, (2020) Impact of the COVID-19 lockdown period on adult musculoskeletal injuries and surgical management: a retrospective monocentric study. Sci Rep 10(1):1-8

Hamd A, Abdulraheem DE, Khan AAP, Shaban M, Alamry KA, Asiri AM (2021) Statistical study on the impact of different meteorological changes on the spread of COVID-19 pandemic in Egypt 
and its latitude. Model Earth Syst Environ. https://doi.org/10. 1007/s40808-021-01222-4

IQAir (2020) 2019 World Air Quality Report. Region \& City PM2. 5 Ranking. 34. https://www.greenpeace.org/static/planet4-thailandstateless/2020/02/91ab34b8-2019-world-air-report.pdf

Karkour S, Itsubo N (2020) Influence of the COVID-19 crisis on global PM2. 5 concentration and related health impacts. Sustainability 12(13):5297

Li Q, Zhu Q, Xu M, Zhao Y, Narayan K, Liu Y (2021) Estimating the impact of COVID-19 on the PM2. 5 levels in China with a satellite-driven machine learning model. Remote Sens 13(7):1351

Ma Y, Zhao Y, Liu J, He X, Wang B, Fu S, Yan J, Niu J, Zhou J, Luo B (2020) Effects of temperature variation and humidity on the death of COVID-19 in Wuhan, China. Sci Total Environ 724:138226

Mantecca P, Gualtieri M, Longhin E, Bestetti G, Palestini P, Bolzacchini E, Camatini M (2012) Adverse biological effects of Milan urban PM looking for suitable molecular markers of exposure. Chem Ind Chem Eng Q 18(4-2):635-641

Menebo MM (2020) Temperature and precipitation associate with Covid-19 new daily cases: a correlation study between weather and Covid-19 pandemic in Oslo, Norway. Sci Total Environ 737:139659

Menter T, Haslbauer JD, Nienhold R, Savic S, Hopfer H, Deigendesch N, Frank S, Turek D, Willi N, Pargger H, Bassetti S, Leuppi JD, Cathomas G, Tolnay M, Mertz D, KD, Tzankov A, (2020) Postmortem examination of COVID-19 patients reveals diffuse alveolar damage with severe capillary congestion and variegated findings in lungs and other organs suggesting vascular dysfunction. Histopathology 77(2):198-209

Paital B, Agrawal PK (2021) Air pollution by NO 2 and PM 2.5 explains COVID-19 infection severity by overexpression of angiotensin-converting enzyme 2 in respiratory cells: a review. Environ Chem Lett 19(1):25-42

Pozzer A, Dominici F, Haines A, Witt C, Münzel T, Lelieveld J (2020) Regional and global contributions of air pollution to risk of death from COVID-19. Cardiovasc Res 116(14):2247-2253

Pun VC, Kazemiparkouhi F, Manjourides J, Suh HH (2017) Longterm PM2. 5 exposure and respiratory, cancer and cardiovascular mortality in older US adults. Am J Epidemiol 186(8):961-969

Şahin M (2020) Impact of weather on COVID-19 pandemic in Turkey. Sci Total Environ 728:138810

Sharma VK, Jinadatha C, Lichtfouse E (2020) Environmental chemistry is most relevant to study coronavirus pandemics. Environ Chem Lett. https://doi.org/10.1007/s10311-020-01017-6

Sun S, Han J (2021) Unflushable or missing toilet paper, the dilemma for developing communities during the COVID-19 episode. Environ Chem Lett 19(1):711-717

Tan J, Mu L, Huang J, Yu S, Chen B, Yin J (2005) An initial investigation of the association between the SARS outbreak and weather: with the view of the environmental temperature and its variation. J Epidemiol Community Health 59(3):186-192

UNEP (2016) GEO-6 Regional Assessment for West Asia. United Nations Environment Programme, Nairobi, Kenya. http://www. unep.org/publications
Van Doremalen N, Bushmaker T, Morris DH, Holbrook MG, Gamble A, Williamson BN, Tamin A, Harcourt JL, Thornburg NJ, Gerber SI (2020) Aerosol and surface stability of SARS-CoV-2 as compared with SARS-CoV-1. N Engl J Med 382(16):1564-1567. https://doi.org/10.1056/NEJMc2004973

Wang L, Li M, Yu S, Chen X, Li Z, Zhang Y, Jiang L, Xia Y, Li J, Liu W, Li P, Lichtfouse E, Rosenfeld D, Seinfeld JH (2020) Unexpected rise of ozone in urban and rural areas, and sulfur dioxide in rural areas during the coronavirus city lockdown in Hangzhou, China: implications for air quality. Environ Chem Lett 18(5):1713-1723. https://doi.org/10.1007/s10311-020-01028-3

Weiss NA (2015) Elementary statistics. Pearson

WHO (2020a) Coronavirus disease 2019 (COVID-19) Situation Report - 91. https://www.who.int/docs/default-source/coronaviruse/situa tion-reports/20200420-sitrep-91-covid-19.pdf

WHO (2020b) Modes of transmission of virus causing COVID-19: implications for IPC precaution recommendations. Retrieved from https://www.who.int/news-room/commentaries/detail/modes-oftransmission-of-virus-causing-covid-19-implications-for-ipcprecaution-recommendations

Xie J, Zhu Y (2020) Association between ambient temperature and COVID-19 infection in 122 cities from China. Sci Total Environ 724:138201. https://doi.org/10.1016/j.scitotenv.2020.138201

Xing YF, Xu YH, Shi MH, Lian YX (2016) The impact of PM2.5 on the human respiratory system. J Thorac Dis 8(1):E69-E74. https:// doi.org/10.3978/j.issn.2072-1439.2016.01.19

Yadav IC, Devi NL (2018) Biomass burning, regional air quality, and climate change. Earth Systems and Environmental Sciences. Edition: Encyclopedia of Environmental Health. Elsevier. https://doi. org/10.1016/B978-0-12-409548-9.11022-X

Yao TT, Qian JD, Zhu WY, Wang Y, Wang GQ (2020) A systematic review of lopinavir therapy for SARS coronavirus and MERS coronavirus - a possible reference for coronavirus disease-19 treatment option. J Med Virol 92(6):556-563. https://doi.org/10. 1002/jmv.25729

Zhu L, Liu X, Huang H, Avellán-Llaguno RD, Lazo MML, Gaggero A, Soto-Rifo R, Patiño L, Valencia-Avellan M, Diringer B, Huang Q, Zhu Y (2020a) Meteorological impact on the COVID-19 pandemic: a study across eight severely affected regions in South America. Sci Total Environ 744:140881. https://doi.org/10.1016/j. scitotenv.2020.140881

Zhu N, Zhang D, Wang W, Li X, Yang B, Song J, Zhao X, Huang B, Shi W, Lu R, Niu P, Zhan F, Ma X, Wang D, Xu W, Wu G, Gao GF, Phil D, Tan W (2020b) A novel coronavirus from patients with pneumonia in China, 2019. N Engl J Med 382:727-733. https://doi.org/10.1056/NEJMoa2001017

Zoran MA, Savastru RS, Savastru DM, Tautan MN (2020) Assessing the relationship between surface levels of PM2. 5 and PM10 particulate matter impact on COVID-19 in Milan, Italy. Sci Total Environ 738:139825. https://doi.org/10.1016/j.scitotenv.2020. 139825

Publisher's Note Springer Nature remains neutral with regard to jurisdictional claims in published maps and institutional affiliations. 